
movimento migratório do consumo de produtos de beleza. Consumer Behavior Review, 4(1), 19-37.

ISSN: 2526-7884

Editor: Prof. Dr. Marconi Freitas da Costa Journal's e-mail: cbr@ufpe.br
Evaluation: Double blind review

Received: 26 de novembro de 2019

Accepted: 28 de janeiro de 2020

\title{
SOU HOMEM COM H! O MOVIMENTO MIGRATÓRIO DO CONSUMO DE PRODUTOS DE BELEZA
}

I'm a man with h! The migratory movement of the consumption of beauty products

\author{
Aryane Ribeiro Maximo ${ }^{1}$ \\ ORCID: https://orcid.org/0000-0003-3932-5446 \\ E-mail: aryanerm@gmail.com \\ Ramon Silva Leite ${ }^{1}$ \\ ORCID: https://orcid.org/0000-0003-2212-9510 \\ E-mail: ramonsl@pucminas.br
}

${ }^{1}$ Pontifícia Universidade Católica de Minas Gerais, Belo Horizonte, Brasil

\begin{abstract}
Resumo
As pesquisas de marketing não acompanharam as mudanças do homem moderno para o hodierno. 0 que antes era caracterizado como "coisa de homem", na contemporaneidade fragmentou-se em novas possibilidades de construção de identidade de gênero, abrindo espaço para o consumo do homem, fragmentando-se em perfis de consumo antes caracterizados como sendo exclusivamente das mulheres, como o consumo de produtos de beleza. Esse estudo buscou compreender como os homens percebem os reflexos desse consumo na sociedade atual. Para isso foram realizadas 12 entrevistas com homens jovens de Belo Horizonte analisadas por meio de análise de
\end{abstract}

\begin{abstract}
Marketing research has not kept pace with the changes of modern man to modern day. What was once characterized as "man thing", in the contemporary era, has fragmented into new possibilities for the construction of gender identity, opening space for the consumption of man, breaking up into profiles of consumption previously characterized as exclusively of women, such as the consumption of beauty products. This study sought to understand how men perceive the reflexes of this consumption in the current society. Twelve interviews with young men from Belo Horizonte were analyzed through content analysis. The results point to an increasingly safe consumer who is still enveloped by stereotypes and prejudice from
\end{abstract}


conteúdo. Os resultados apontam para um consumidor cada vez mais seguro, mas que ainda está envolto por estereótipos e preconceito da sociedade.

Palavras-chave: Consumo migratório; Vaidade masculina e preconceito; Autoafirmação masculina; Consumo simbólico. society.

Key-words: Migratory consumption; Male vanity and prejudice; Men self-affirmation; Symbolic Consumption.

Esta obra está licenciada com uma Licença Creative Commons Atribuição 4.0 Internacional.

\section{INTRODUÇÃO}

De acordo com Garcia (2011, p. 71) "nota-se a necessidade de considerar, investigar e acordar as mudanças da sociedade contemporânea, bem como algumas representações imensuráveis na atualidade, que tangem a masculinidade". Nesse sentido, o autor complementa que "surge a oportunidade de realizar uma leitura minuciosa, inerente à cultura masculina" (Garcia, 2011, p. 91). Para Souiden e Diagne (2009) as empresas têm apostado e concentrado seus investimentos em produtos de nicho, para garantir penetração de mercado e aumentar suas cotas de participação de mercado. Assim, Fritz e Gomes de Souza (2006) observam que há uma grande aceitação de produtos de beleza para públicos diferenciados, como o público masculino, cujo volume total de vendas evoluiu nos últimos anos, tendência acompanhada pelo aumento da vaidade masculina.

Garcia (2004) salienta que o homem vaidoso passou a ser conceituado como um homem metrossexual, termo que surgiu em 1994 e conceitua esse consumidor como um homem jovem urbano e que gasta boa parte do seu dinheiro com cuidados estéticos para o próprio corpo. Mais tarde Garcia (2011, p. 121) define esse homem como obcecado pela aparência superficial, e complementa que "o metrossexual parece manter o lugar da virilidade de forma tranquila. Assim, faz emergir um novo tipo de gênero masculino, surgindo nas grandes cidades do país e do mundo". No entanto, alguns autores relatam que ainda há muito preconceito em torno do comportamento metrossexual ou do homem vaidoso, muitas vezes confundido como um homem que se aproxima dos comportamentos femininos de consumo (Carvalho, 2010; Nobusada, 2011; Castro, 2011; Ceotto, 2013; Infante et. al. 2016), o que Garcia (2011) e Oliveira (2008) discordam, e complementam que apesar de haver no brasileiro uma repulsa com o comportamento, esta é uma mudança no hábito de consumo do homem que crescerá cada vez mais e que nada tem a ver com a sua identidade de gênero.

Lucerna (2006) evidencia ser nítido o aumento do uso de cosméticos por homens. Contudo, apesar da importância crescente do segmento, pouca atenção é dada à investigação sobre o consumo dos homens em relação a tais produtos (Souiden \& Diagne, 2009). É preciso, então, conhecer melhor o consumidor masculino, uma vez que, historicamente, não é com esse público que pesquisadores e acadêmicos costumam dialogar com mais frequência, dando ênfase ao mainstream feminino (Michael weber \& Villebonne, 2002; Souiden \& Diagne, 2009). Há estudos norte americanos, europeus e asiáticos analisando esse novo consumidor masculino desde o início da década de 2000, mas na literatura brasileira encontrou-se poucos estudos relacionados ao consumidor vaidoso. Os estudos ainda são incipientes em relação às variadas possibilidades que esse mercado apresenta (Michael Weber \& Villebonne, 2002; Souiden \& Diagne, 2009; Garcia, 2011; Kim et al., 2013). Esse movimento migratório no consumo de produtos de beleza evidencia uma tendência de consumo na vida do homem (Castro, 2011; Oliveira \& Leão, 2012), mas que demanda aprofundamento dos estudos na esfera acadêmica.

Para Sant'anna $(2005$, p. 95) a vaidade masculina é uma realidade que vem acontecendo ao longo do século XX, mas que vem sendo constatada nos últimos séculos de forma gradativa. Para esse autor, há um novo modelo de homem "cuja personalidade é fragmentada e multifacetada, que vem sendo definido e observado como um fenômeno social" de impacto na sociedade de consumo e indústria em geral. Em acordo com a colocação de Sant'anna (2005), Vieira-Senna (2011) considera 
haver um "desdobramento do homem em perfis traçados de acordo com as ofertas de mercado e suas escolhas de consumo" com características do homem "macho", que faz questão de ressaltar o modelo de masculinidade hegemônica da sociedade patriarcal, e do homem "sensível" da segunda metade do século XX, que usa cosméticos, perfumaria e produtos da moda. Na década de 80, segundo Gama e Vasconcelos (2011), os homens tornaram-se mais preocupados com a aparência, e segundo Garcia (2011, p. 13) um dos motivos dessa mudança de comportamento dos homens é devido a cobrança por melhor aparência do mercado de trabalho, além de melhorar os relacionamentos amorosos e em sociedade. Em uma pesquisa mais recente, Maximo e Leite (2019) evidenciaram que os homens adotam posturas relacionadas ao cuidado com a sua aparência condizentes aos seus relacionamentos em sociedade.

É interessante acrescentar que os estudos analisados sobre o "novo homem" abordam, de forma aparentemente unânime, esse movimento como um assunto estritamente midiático, sem enfatizar o fenômeno sob a ótica do consumo, como por exemplo nos trabalhos de Garboggini (1999), Garcia (2004), Garboggini (2008), Freitas (2011) e Oliveira Junior (2012). Nesses termos, talvez seja importante desviar-se da ideia de que esse homem seja um consumidor influenciado pela mídia, como vem sendo abordado em alguns estudos, buscando estudar o tema de forma a preencher essa lacuna no campo do marketing, possibilitando pesquisas em busca do entendimento deste consumidor que tem ganhado a atenção da indústria, mas que ainda carece de estudos na área acadêmica (Souiden \& Diagne, 2009). Nesse sentido, diante de um comportamento envolto por preconceitos, esse estudo buscou compreender como o homem vaidoso percebe os reflexos do seu consumo na sociedade atual.

\section{REVISÃO DA LITERATURA}

0 que antes era envolto por padrões socioculturais, atualmente passa a ser ditado pelo consumo. Assim, o que uma pessoa consome lhe dá mecanismos para interação com a sociedade em determinados grupos e imprime características sobre a sua identidade. Há uma relação, portanto, entre a identidade da pessoa e o que ela usa. Assim, a identidade é tanto social quanto simbólica (Woodward, 2000).

Bodart (2014) elucida algumas mudanças na estrutura social que foram importantes para a atual configuração da vaidade entre os homens, dentre elas, o desenvolvimento do capitalismo e as mudanças ocorridas no seio do cristianismo. Segundo o autor o capitalismo visando ampliar o lucro das empresas, busca cada vez mais incluir os homens no consumo de produtos que, até pouco tempo, eram destinados apenas às mulheres. Ademais, a preocupação com a beleza passou a ser tolerada pelo cristianismo, entretanto com uma conotação negativa, provocando uma ampliação da distância entre o que seria cuidar da aparência como ato saudável e o que seria vaidade.

Um levantamento bibliográfico sobre as publicações do novo homem a partir de 1930 foi realizada por Neri e Tarquini (2015). Os autores constataram que vivemos um momento de ressignificação da identidade do homem na sociedade, uma vez que a princípio, as discussões eram centradas em entender se as características deste fenômeno de consumo sobre a vaidade masculina, compreendia todos os homens, independentemente de sua sexualidade, ou se era algo relacionado exclusivamente aos homossexuais, uma vez que historicamente o cuidado com a vaidade é relacionado as mulheres. Para os autores, "a convergência de cultura homossexual e heterossexual a partir dos anos 90 também é apontada como um dos fatores que colaboram para o surgimento desse estilo de consumir no universo masculino.

A colocação de Kacen (2000) concerne com a ideia de Oliveira e Leão (2011), que coloca a identidade como um instrumento de autoexpressão, indo de encontro com as teorias de Baudrilard (2003) sobre a sociedade do consumo e sua capacidade de desenvolver uma hierarquia social que cria identidades neste meio, a partir do aparato de signos e símbolos que o consumo oferece. Slater (2002) afirma ainda que é por meio do uso de bens e serviços que nos formulamos enquanto identidades sociais, corroborando com as constatações de Campbell (2006). Maximo e Leite (2017) conduziram uma análise de Cluster pela qual foram definidos seis perfis de homens metrossexuais ao qual concluíram que esse consumidor demonstra sua vaidade nos extremos, em que o nada vaidoso corrobora com uma visão machista dos papeis masculinos, e aquele que busca pela beleza utópica 
amplia as concepções de identidade de gênero, como identidades sociais formuladas e impactadas pelo consumo e pelas relações em sociedade.

Oliveira e Leão (2011) concluem que o século XXI trouxe para a sociedade várias novas tendências de consumo, baseadas, a princípio, em novos estilos de vida dos consumidores. Antes havia a exigência do padrão de beleza feminino, e hoje essa exigência, que ainda é forte para as mulheres, se estende aos homens, o que descaracteriza a estabilidade sólida do gênero masculino. Esse novo parâmetro de consumo do homem estimula o consumo e oferece um patamar ao mercado, já que se espera que eles estejam cada vez mais bem cuidados, bonitos e atraentes (Kacen, 2000).

Comparando alguns padrões de consumo de homens e mulheres e, em busca de romper com alguns padrões ditos como masculinos ou femininos, Garcia (2011, p. 87) entende que o fato de valorizar a aparência com tratamentos estéticos de beleza já foi, no passado, uma posição "machista" ao considerar o cuidado com o corpo como especificamente "coisa de mulher", dizendo ser essa uma ideia ultrajante, como se a vaidade pudesse ser eleita a partir da divisão binária de gênero masculino ou feminino. A filósofa Judith Butler criticou esse modelo de divisão binária, considerando que esse fracionamento arbitrário dos papéis femininos e masculinos, e de divisão sexo/ gênero, é arbitrária e defende que o sexo é natural e o gênero é socialmente construído, no qual surgem as identidades de gênero, e essa associação do feminino com fragilidade ou submissão, servem para justificar preconceitos (Butler, 2003), que atingem homens e mulheres. Para tal, Fontes, Borelli e Casotti (2010) defendem que o preconceito com relação aos papéis dos gêneros ainda é latente e, complementam que, enquanto o homem consumir menos produtos e serviços de beleza que a mulher, estará garantida a diferenciação entre os sexos.

Segundo Gikovate (1987), a cultura ocidental estimula o exibicionismo físico feminino, e até pouco tempo, reprimia ostensivamente o exibicionismo físico masculino, já que tais comportamentos eram ligados a homossexualidade, mas hoje esse comportamento masculino ligado a vaidade está se tornando cada vez mais socialmente aceito. Assim, "com a noção de gênero conceituadamente dissolvida pela fragmentação contemporânea, testemunha-se o declínio das representações cristalizadas. Esse declínio visa abrir novos rumos e novas opções" (Garcia, 2011, p. 89).

Para Gikovate (1989), os padrões de comportamento socialmente aceitáveis estão prontos. Os meninos devem seguir normas próprias do seu sexo, e o mesmo acontece com as meninas, contudo, atualmente, os comportamentos de consumo entre homens e mulheres são muito mais sinérgicos. Para Gikovate (1987), o mercado percebe essa tendência e complementa concluindo que, cremes de beleza e outros produtos tradicionalmente femininos começam a ser produzidos para homens e extrapola, também, para os serviços, antes ditos como femininos, tornando-se práticas unissex. 0 autor ainda aborda, na sua obra, que essa mudança no comportamento masculino em virtude da sua vaidade, está totalmente enraizada na vontade de se fazer percebido nas relações sociais (Gikovate, 1987; Gikovate, 1989).

Se por um lado as mudanças socioculturais impactaram os papeis femininos na sociedade, favorecendo a revolução feminista e o acesso da mulher a colocações antes impensadas, surge a figura do novo homem, com apelos consumistas aflorados (Garcia, 2004; Pinho, 2004). Villaça apud Garcia (2011) complementa que, na verdade, não se trata de uma pura inversão dos valores femininos, mas sim, uma combinação de fatores econômicos, identitários, socioculturais e políticos, que são repreendidos com um enfoque complexo do consumo masculino.

Os homens, desde criança, foram estereotipados a terem comportamentos e representações sexuais distorcidas que imprimiam a eles os atributos de força, poder, virilidade e "macheza" (Gouveia, 2006; Connel \& Messerschmidt, 2005; Oliveira \& Leão, 2011, Goldenberg, 2000). Para Gouveia (2006, p. 12), "esse modelo tradicional se coaduna ao conceito do patriarcado, estabelecido desde o início da Era Cristã, quando os homens necessitavam demonstrar força para proteger sua terra. Este estereótipo pressupõe a soberania masculina e a subserviência da mulher, em um contexto no qual o homem não demonstra fragilidades, não transmite seus sentimentos, não tem medos ou inseguranças".

Autores como Gouveia (2006), Oliveira e Leão (2011) e Connell (2012) concordam que a revolução feminista, das décadas de 60 e 70, estabeleceu um novo marco no consumo masculino, assim como mudanças no contexto cultural. A princípio a emancipação feminina representou o 
surgimento de uma "nova mulher", dotada de mais independência, autoestima, e fazendo surgir a figura do "novo homem", do qual "foi impelido a adotar um novo posicionamento na sociedade e na família" (Gouveia, 2006). Estudiosos de várias áreas têm debruçado suas pesquisas sob o olhar feminino e as suas transformações no consumo. Devido a esse mainstream de pesquisa, os estudos considerando a mudança no consumo masculino tem sido mais silenciosa e lenta (Gouveia, 2006).

Popcorn (1997) retrata que o homem está se emancipando e salienta que a tendência é dele se libertar de estigmas machistas, e que suas atitudes não precisam ser pragmáticas, comedidas e analíticas, mas que sejam mais sentimentais. No passado, o homem foi vaidoso, mas após a revolução industrial esse seu lado desapareceu. Essa nova tendência, relatada por Popcorn (1997), demonstra que o homem hodierno tende a ser mais vaidoso e busca ser mais atraente. Fato constatado na pesquisa de Sayon (2017) que questionou se o consumo de cosmético por homens é uma questão de vaidade ou de reforço da masculinidade. Descobriu-se que tanto a vaidade quanto a masculinidade possuem efeito positivo sobre o consumo de cosméticos.

Penn (2008) também aborda essa mudança de comportamento no âmbito masculino, evidenciando que hoje os homens passaram a se preocupar mais com a aparência. Maximo (2015) realizou um estudo sobre o comportamento do consumidor masculino que apurou a existência de um frequente consumo de serviços e produtos cosméticos para cuidar da aparência. A autora realizou uma análise da frequência de consumo com a definição de um escore para analisar a frequência de uso de diversas categorias e tipos de produtos cosméticos, o que possibilitou conhecer os produtos preferidos destes consumidores, corroborando com a visão de Penn (2008) sobre a mudança de comportamento deste público de consumidores.

Para Bastos (2005), "estes novos homens estão muito à frente do estereotipo de "macho" crucificado nos anos 90 pelas feministas (...). Eles estão deixando florescer suas emoções e reconhecendo a necessidade de manter uma boa aparência".

Em relação aos produtos ligados a aparência física, como os cosméticos, Castro (2011) descreve que a relação do homem com os cuidados pessoais demonstram uma característica dicotômica, em uma relação de oposição entre a vaidade equilibrada e a vaidade excessiva, também destacado por Abdala (2008) que divide a vaidade em equilibrada e extrema. 0 estudo de Castro (2011) apontou que a vaidade masculina tem duas facetas: uma positiva (vaidade equilibrada) em que o homem médio cuida de si mesmo mas dentro de um "padrão de normalidade", e que, traz sensação de bem-estar e associações positivas; E, outra oposta, com características negativas (vaidade excessiva), relacionadas ao homem que adota posturas que não se encaixam no padrão do homem médio. Estas características estariam associadas a futilidade, além de apontar um comportamento que, na visão do homem médio, se aproximaria dos padrões tradicionalmente mais femininos no que tange aos cuidados pessoais. Esta constatação de Castro (2011) pode ser comparada a percepção de Lipovetsky (1944) de hedonismo bem temperado, que mesmo dito como sendo normal, ainda assim caracterizam concepções de consumo hedonista.

E assim, Garcia (2011, p. 93) questiona e constata o seguinte: "Imagine o que poderia ser, hoje, um macho convicto? É dar adeus ao retro com quem se distancia da barbárie e da selvageria! De fato, esse típico macho, classe média, está longe de ser um brucutu e, cada vez menos, preconceituoso em relação ao cuidar de si.". O autor ainda complementa dizendo que apesar de todo o preconceito enfrentado pelo "novo homem" sobre a sua masculinidade, o consumo de vaidade nada tem a ver com a conotação sexual. Apesar de serem estereotipados como homossexuais esses homens estão cada vez mais seguros em relação ao consumo de produtos para beleza e estão fazendo crescer no Brasil o consumo de produtos cosméticos (Garcia, 2011), que é atualmente o 4 o mercado do mundo, segundo a Associação Brasileira da Indústria de Higiene Pessoal, Perfumaria e Cosméticos (ABIHPEC, 2016).

\section{MÉTODO DE PESQUISA}

0 presente estudo constitui uma proposta de análise do consumo de cosméticos por homens jovens, moradores da Região Metropolitana de Belo Horizonte, a fim de identificar fatores que esclareçam como os homens percebem os reflexos do seu consumo na sociedade atual, que ainda rotula tais comportamentos de compra de forma preconceituosa. Considerou-se, para esse estudo, a 
definição de Papalia, Olds e Feldman (2006), para o qual, jovens adultos são pessoas na faixa de idade de 20 à 40 anos. Foi realizada uma pesquisa qualitativa com doze homens, por meio de entrevistas em profundidade e complementadas por técnicas projetivas.

Inicialmente, a escolha dos entrevistados ocorreu por conveniência dos pesquisadores, selecionando homens com características de vaidade evidentes no seu cotidiano. No processo de pesquisa foi possibilitado ao entrevistado indicar outros homens que tivessem características de vaidade, principalmente devido ao fato de os homens demonstrarem uma dificuldade cultural para declarar o uso de produtos cosméticos. Por isso, considerou-se como prerrogativa nesse estudo a inspiração de indicação do tipo bola de neve, em que entrevistados são selecionados com base em informações fornecidas por entrevistados iniciais (Malhotra, 2001; Aaker et al, 2004). Para Aaker et al (2004) no método de bola de neve as indicações se dão pelos próprios entrevistados, no qual estes recomendam outros de iguais características e assim por diante, até que o número-alvo de pesquisados seja alcançado.

Na concepção do corpus dessa pesquisa, optou-se por adotar o critério qualitativo da saturação de Gaskell (2002), Bauer e Aarts (2002) e também referenciado por Marre (1991). Para Gaskell (2002), Bauer e Aarts (2002), a quantidade de entrevistas da pesquisa qualitativa está relacionada a saturação do tema, dessa forma, um número maior de entrevistas não, necessariamente, eleva a qualidade da pesquisa ou leva a maior compreensão do tema, já que existe um "número limitado de interpelações ou versões da realidade". Para atender os objetivos dessa pesquisa, foram entrevistados 12 homens, usando um roteiro semi-estruturado, entre os dias 30 de maio de 2014 e 22 de julho de 2014, moradores de Belo Horizonte e região metropolitana, com idades entre 19 e 38 anos.

Considerando a proposta de Aaker, Kumar e Day (2001), a pesquisa qualitativa tem o propósito de descobrir o que o consumidor tem em mente, e fomenta a compreensão do escopo e das complexidades das atividades e preocupações dos consumidores. A pesquisa qualitativa busca compreender os pensamentos, as ações, os sentimentos, as emoções e as motivações das pessoas e parte do princípio de que essas emoções, motivações e atitudes podem ser reveladas de forma indireta, utilizando-se para isso estímulos pouco estruturados (Aaker, Kumar, \& Day, 2001), cujos significados e compreensão possuem um caráter interpretativo (Creswell, 2003). Diante disto, após realizada a revisão da literatura, foi construído um roteiro de entrevista semiestruturado, considerando questões de roteiros já utilizados por Davidovitsch (2007), Abdala (2008), Oliveira (2008), Cheng, Ooi, Ting (2010), Kyung (2012), Oliveira Junior (2012) e Resende et al. (2014), para levantar as principais variáveis relacionadas ao tema.

Segundo Haire (1950), quando um consumidor é abordado com questões diretas sobre sua reação a algum produto, geralmente sua reação acaba sendo duvidosa e pouco compreendida. Em sua pesquisa, o autor concluiu que existem motivações abaixo do nível de verbalização porque algumas são socialmente inaceitáveis, dificultando que se fale sobre determinado ponto, bem como o seu reconhecimento. Haire (1950) destaca ainda que geralmente essas decisões estão relacionadas a comprar ou não e que elas são possíveis de serem identificadas se abordadas de maneira indireta. Para Vieira e Tibola (2005), é possível adotar a técnica projetiva quando a informação desejada não pode ser obtida com precisão por métodos diretos. Para os autores, trata-se de uma pesquisa exploratória para proporcionar entendimento e compreensão inicial.

Segundo Easterby-Smith, Thorpe e Lowe (1999, p. 87), as técnicas projetivas se baseiam no princípio de que "as pessoas revelam níveis ocultos de sua consciência reagindo a diferentes tipos de estímulos". O objetivo nessa pesquisa, com a adoção da técnica projetiva, foi captar percepções e concepções que não foram ditas na entrevista e que se fundamentam apenas na verbalização, principalmente, ao considerar que algumas das respostas seguem um padrão ou tendência do "socialmente aceitável" ou mesmo não captam aspectos inconscientes e menos racionais que são importantes para a compreensão do fenômeno ou evento em estudo (Seltiz, Wrightsman \& Cook, 1976; Loizos, 2002; Nossiter \& Biberman, 1990).

Para alcançar tal objetivo, foram utilizadas a técnica projetiva de conclusão, de associação e de construção (Malhotra, 2011). Primeiro, os entrevistados foram convidados a complementar frases que buscaram identificar o comportamento do homem vaidoso como, "Quando um homem sai para comprar cosméticos ele..." e, “Um homem nunca compra...”. Estas duas questões foram amparadas na 
técnica projetiva, conhecida como técnica de conclusão. Uma outra técnica utilizada foi a de associação, ao solicitar aos entrevistados realizar um exercício imagético sobre como eles caracterizam o homem metrossexual e também ao questionar "Como você nomearia o homem preocupado com a aparência, vaidoso, que gosta de usar produtos de grife, passa creme no corpo, vai à manicure e pedicure, gosta de frequentar shoppings, que sabe sobre moda, gastronomia, vinhos...?", conceito elaborado por Oliveira Junior (2012) para caracterizar o homem vaidoso e metrossexual. Essa técnica se baseia nas conexões literais que as pessoas fazem quando estão construindo uma narrativa (Bond \& Ramsey, 2010; Vergara, 2008).

Por fim, foi utilizada a técnica de construção com a apresentação de fotos de homens famosos que se declaram na mídia como muito vaidosos e metrossexuais. Com o intuito de não deixar definido um estilo de metrossexual, foram apresentados vários perfis de homens, em fotos que demonstram as suas atuações profissionais. 0 primeiro deles, Anderson Silva, 39 anos, casado, cinco filhos e lutador de MMA. O segundo, David Beckham, também muito reconhecido por ser o ícone dos metrossexuais, 39 anos, casado, quatro filhos e ex-jogador de futebol. Justin Timberlake com 33 anos, solteiro, sem filhos e cantor. E, Roberto Justus, que tem 59 anos, divorciado, quatro filhos, empresário e apresentador de programas na televisão aberta. As informações destes homens estão descritas aqui conforme apresentadas aos entrevistados na época da entrevista. Nesta etapa da entrevista, foi solicitado que o entrevistado indicasse com quem mais se identificava; depois foi pedido que indicasse quem o entrevistado achava que poderia ser metrossexual; e por fim, era revelado que o artista escolhido era metrossexual. Foi analisado o comportamento dos entrevistados ao ser revelado que o homem da foto era metrossexual em busca de elucidar emoções, sentimentos e comportamentos que destoassem do discurso inicial sobre a vaidade dos homens, presumidamente como algo natural.

As entrevistas foram presenciais, agendadas previamente, em dia e horário de preferência dos entrevistados. Antes de iniciar cada entrevista, foi solicitado a autorização e aceite para participar da pesquisa, demonstrando o caráter exclusivamente acadêmico da coleta. A duração média de cada entrevista foi de aproximadamente 22 minutos, havendo quatro de duração superior à 50 minutos, e dependeu exclusivamente do ritmo do entrevistado para responder aos questionamentos; evitou-se, assim, comprometer a qualidade da coleta dos dados. As entrevistas foram realizadas nas residências, local de trabalho ou academia onde o entrevistado é frequentador. Foi utilizada uma sala apropriada, sem a presença de outras pessoas, com silêncio e privacidade, um ambiente que proporcionou conforto, tranquilidade e segurança para se desenvolver as entrevistas.

Cada uma das entrevistas foi gravada, transcrita e analisada separadamente. Utilizando-se de Bardin (2004) como referência, as análises desse estudo foram realizadas em duas etapas: a préanálise, realizada a partir de uma leitura aberta dos textos, a codificação e a categorização, por meio do agrupamento dos temas identificados usando o software Atlas T.I. A codificação e categorização realizada neste estudo podem ser identificados a seguir no quadro 1.

\begin{tabular}{|c|l|}
\hline \multicolumn{1}{|c|}{ Categorias } & \multicolumn{1}{|c|}{ Códigos Associados } \\
\hline \multirow{4}{*}{ Vaidade masculina } & O que acha feio em homem (9) \\
& Vaidade do metrossexual (13) \\
& Vaidade exagerada (33) \\
& Vaidade masculina (33) \\
\hline \multirow{4}{*}{ A autoimagem } & A minha vaidade (30) \\
& Como as pessoas me veem (5) \\
& Como eu me vejo (32) \\
& 0 espelho (32) \\
& O eu narciso (28) \\
\hline \multirow{5}{*}{ Relacionamentos sociais } & A aparência como vitrine (25) \\
& Amizade com metrossexuais (13) \\
& Referencias pessoais (3) \\
& Relacionamento amoroso (13) \\
& Seria amigo do metrossexual (12) \\
& Vaidade para as mulheres (8) \\
\hline
\end{tabular}




\begin{tabular}{|l|l|}
\hline \multirow{2}{*}{ Envolvimento com produtos, marcas e lojas } & $\begin{array}{l}\text { Fidelidade ao produto (26) } \\
\text { Identificação com marca ou loja (22) } \\
\text { O que valoriza ao comprar (10) } \\
\text { Sensação de compra (9) }\end{array}$ \\
\hline
\end{tabular}

Fonte: Elaborado pelos autores.

Nota. 0 número entre parênteses representa a quantidade de citações relacionadas a cada código.

Quadro 1. Categorias e códigos associados

Para o tratamento dos dados foi utilizada a análise de conteúdo (Bardin, 2004), em que se procurou compreender o conteúdo efetivo da fala dos entrevistados sobre o objeto do estudo, como poderá ser apreciado na seção seguinte.

\section{ANÁLISE DOS RESULTADOS}

$\mathrm{Na}$ pesquisa foram abordadas questões relativas a vaidade, e os entrevistados eram convidados a pensar sobre a sua vaidade pessoal e sobre homens vaidosos. Em outros momentos da entrevista, em que eram abordadas questões como autoimagem, consumo de cosméticos e sobre o metrossexual, o assunto vaidade apresentou ser um tema recorrente. A literatura aborda o metrossexual como um homem vaidoso e que explora os produtos cosméticos em busca da boa aparência, e por isso nesse estudo tornou-se necessário incorporar o conceito nas discussões com os consumidores pesquisados. No entanto, mesmo antes de incorporar o conceito na entrevista, por diversas vezes, logo no início das conversas, a vaidade masculina era vinculada ao metrossexual pelos próprios entrevistados.

"Eu sou bem vaidoso comigo, mas as pessoas visualizam ah aquele rapaz é muito vaidoso, ele é gay, ah aquele rapaz é muito vaidoso ele é metrossexual" (Entrevista 01).

Sobre a vaidade masculina é unânime entre os entrevistados dizer que o homem deve ser vaidoso e que é muito importante hoje em dia o homem preocupar-se com a vaidade. Assim percebese a crescente preocupação dos homens com a vaidade, iniciando, portanto, as denotações a respeito da migração do consumo de vaidade outrora percebido como de domínio feminino.

"O homem tem que se cuidar, isso fica muito mais evidente na mulher. A mulher gosta de se cuidar e o homem gosta da mulher que se cuida, e eu sou desses homens que gosta da mulher que se cuida, então eu também tenho que fazer a minha parte. Um homem que se cuida e tem esse embasamento, se a mulher se cuida eu também tenho que me cuidar, para agradá-la. " (Entrevista 02).

"Todo mundo tem que ser vaidoso. Todo mundo. Homens e mulheres" (Entrevista 04).

Para estes homens a vaidade é expressa muito naturalmente, desde que dentro dos ditos parâmetros normais. $O$ interessante é que a vaidade pessoal do entrevistado era sempre mencionada como natural ou normal, mesmo que esse entrevistado fosse um consumidor fiel de diversos produtos cosméticos e serviços estéticos. Às vezes, ao mencionar os cuidados de um amigo ou um artista famoso, esse homem relatava que haveria, nesse caso, um exagero na vaidade pessoal. Assim, as práticas pessoais do entrevistado eram sempre definidas como práticas de uma vaidade equilibrada. Para Castro (2011), a atribuição a uma vaidade equilibrada estaria ligada a busca desse homem por uma racionalidade na ação e consumo desses produtos, como uma negação da busca pelo ideal de beleza vigente.

Representa, também, uma busca de não demonstrar uma vaidade exagerada, muitas vezes compreendida como de domínio feminino. Dessa forma, a vaidade masculina seria uma vaidade 
equilibrada e positiva, relacionada a um cuidado individual consigo mesmo, além de uma vontade de se sentir bem perante os próprios olhos e aos olhos do outro.

\begin{abstract}
"Vamos pensar assim, quando um homem faz um mínimo necessário da higiene eu diria que ok, é um homem que não se preocupa tanto, ele se preocupa com a limpeza e tudo mais. Quando ele vai além dos princípios básicos da higiene, tomar banho não sei o quê, ele começa a se preocupar em fazer alguns tratamentos, algumas modificações talvez, além do que é básico para higiene eu acho que ele já começa a entrar no grupo dos homens vaidosos" (Entrevista 02).

“Tá! Uma pessoa que se cuida, se cuida! Não num sentido do exagero. Preocupa, vaidosa num sentido de se sentir preocupada consigo, preocupada com o corpo pra que todas as pessoas que estão em contato com ela, principalmente nessa questão da higiene" (Entrevista 06).
\end{abstract}

Esses discursos evidenciam a posição de Fontes, Borelli e Casotti (2010) sobre o preconceito com relação aos papéis dos gêneros nos hábitos de consumo. Contudo, estes homens estão consumindo cada vez mais produtos cosméticos, e por isso, para garantir diferenciação entre os sexos, citada pelos autores, eles definem o hábito de consumo, como uma vaidade equilibrada. Observa-se que o discurso está enraizado no consumo simbólico retratado por Campbell $(2001$, p. 115) para o qual "o indivíduo é muito mais um artista da imaginação, alguém que tira imagens da memória ou das circunstâncias existentes e as redistribui ou as aperfeiçoa de outra maneira em sua mente".

Esses homens também conseguem definir diferenças entre homens vaidosos e homens não vaidosos, caracterizando muitas vezes o homem vaidoso como aquele que segue os mesmos padrões pessoais do entrevistado com cuidados relacionados a vaidade.

"As principais diferenças elas estão expostas bem visualmente neh, você vê que a pessoa não tem vaidade, você vê que a pessoa não tem um porte (...), você sabe que a pessoa não se cuida só de ver, não tem como disfarçar não, é perceptível em cada um" (Entrevista 03).

A vaidade diz respeito a busca em estar bem aparentemente e de um visual bem cuidado, e que demonstre saúde, confirmando a pesquisa de Dion, Berscheid e Walster (1972), que conclui que as pessoas tendem a considerar as pessoas com melhor aparência como mais saudáveis. Conforme explicitado por Oliveira (2008), o bem-estar deste homem ocorre por meio de sua vaidade, dos cuidados consigo mesmo, e assim ele se sente bem, estando arrumado e quando se olha e gosta da imagem que vê refletida no espelho. Para esses homens, uma das principais diferenças entre um homem vaidoso e um não vaidoso significa ter ou não amor próprio, ou gostar ou não de se cuidar.

"Eu gosto de ter uma aparência legal e para ter uma aparência legal eu tomo alguns cuidados que me levam a dizer que eu sou vaidoso. Por exemplo: eu gosto de cortar o cabelo, eu gosto de cuidar da pele, eu gosto de cuidar do corpo, eu gosto de me olhar e ver que eu estou contribuindo para uma boa imagem" (Entrevista 02)

"Eu acho isso bom para a saúde de cada um porque eu acho que a vaidade está bem ligada a saúde" (Entrevista 03).

Há uma congruência entre as falas dos entrevistados e a visão de Levy (1959), que salienta que o consumo de produtos está relacionado a utilidade, mas também pelo o que representa tal consumo na vida dessas pessoas. A relevância dos relacionamentos sociais na vida desse consumidor pode demonstrar que apesar de considerarem as suas idealizações de consumo a respeito da sua vaidade, não deixam de demonstrar a sua preocupação de como querem ser vistos pelos outros e, ademais, sentem seguros de si. 
"O meu objetivo é me sentir melhor comigo mesmo, e consequentemente eu fico mais apresentável" (Entrevista 02)

"Tudo isso que a gente faz é para construir uma imagem mais apresentável para as pessoas" (Entrevista 04).

"Me sinto confortável, me sinto bem também, porque como eu gosto de usar os produtos neh, aí eu me sinto bem. Não só comigo, mas com as pessoas que eu tô me relacionando" (Entrevista 10)

O uso de produtos cosméticos em busca de sentirem-se mais seguros perante os outros está relacionado a busca de estabelecer comunicação com outras pessoas, e, o consumo, são determinantes para o desenvolvimento da identidade pessoal (Piacentini \& Mailer, 2004). Segundo Yoo, Chung e Han (2006) apud Lübeck et. al (2018), "o significado social que o produto transmite, como status e imagem na sociedade, pode representar o motivo principal de sua compra".

Ressalta-se também as combinações de vaidade que as concepções dos entrevistados permitem formar, relacionando o homem vaidoso à saúde, estilo de se vestir, cuidados pessoais de higiene, gostar de si mesmo, gostar de se ver no espelho e gostar de usar produtos cosméticos, além de indicar também os cuidados rotineiros que os homens vaidosos tem no dia a dia. Essa constatação confirma a capacidade do significado simbólico destes produtos na rotina destes homens, conforme conclusões de Belk (1988). "Símbolo é um termo geral utilizado quando a experiência é mediada, em vez de ser direta, fazendo com que um objeto, palavra, imagem ou comportamento complexo signifique não somente ele mesmo, mas também outras ideias ou sentimentos" (Levy, 1959 apud Comassetto et. al (2012).

"Eu sou bem vaidoso comigo. Eu tenho um tempo diário cronometrado para cuidados comigo e usar os produtos que eu gosto" (Entrevista 01)

"Além de ir no salão eu acho que eles preocupam em investir em produtos, produtos de beleza" (Entrevista 10).

"Acho que dá pra ver no jeito de vestir, o jeito de se barbear, jeito de cortar cabelo, o próprio corpo da pessoa, acho que uma pessoa que não é muito vaidosa ela não liga se está com a barriga, se tem um braço um pouco mais tonificado ou não" (Entrevista 09).

Com base nestes relatos é possível definir a vaidade como um comportamento percebido por esses homens como algo positivo, saudável, que vai ao encontro com um cuidado consigo mesmo e para se sentir bem.

"Vou ser bem direto, eu olho no espelho e gosto do que eu vejo" (Entrevista 02).

"Ah quando eu olho no espelho eu fico satisfeito" (Entrevista 04).

"Nossa!!! Um príncipe. Me sinto um príncipe. Me sinto ainda mais valorizado. Ainda mais" (Entrevista 05).

No entendimento deles, o uso de produtos cosméticos traz sensações de prazer, bem-estar, e de cuidado consigo, demonstrando ser um dos motivos para que os homens busquem o consumo desses produtos.

"Eu sinto que eu estou me revitalizando" (Entrevista 03).

"Ah prazer, felicidade, como qualquer consumo neh. Como qualquer consumo, prazer. Satisfação, prazer" (Entrevista 04).

Contudo, apesar de identificar a vaidade como um comportamento saudável, por vários momentos os entrevistados relataram a vaidade exagerada como algo reprovável e que deve ser evitado, aflorando os primeiros indícios de que tal consumo "exagerado" é algo fora do normal da 
rotina do homem, perfazendo nos relatos aspectos relacionados ao preconceito a esse tipo de consumo pelos homens.

"São tão cuidadosos e você fica sem compreender se aquilo é normal ou se é uma possessividade" (Entrevista 01).

Esta conclusão rebate a constatação de Popcorn que em 1997 considerava que o homem começava a se libertar de estigmas machistas, mas que de fato estão sinalizadas nos discursos comedidos como algo distante da realidade destes consumidores, uma vez que imprimem uma afirmativa que busca evidenciar a macheza e masculinidade. Entretanto, há uma ambiguidade nos discursos, ora reconhecendo a necessidade de manter uma boa aparência (Bastos, 2005), outras vezes a negativa em demonstrar a importância desse comportamento na sua realidade, atribuindo ao consumo aspectos negativos como de uma vaidade exagerada, querendo demonstrar uma masculinidade que este homem julga estar "a perigo" na representação do seu consumo cotidiano.

Nesse sentido, apesar dos homens se preocuparem mais com a aparência, a mudança do pensamento em relação a masculinidade hegemônica ocorre mais lentamente em comparação ao aumento nas vendas de produtos cosméticos para homens, contrapondo a percepção de alguns autores, como Penn (2008), Bastos (2005) e Garcia (2011). Todavia, essa necessidade de autoafirmação masculina é estimulada pelo preconceito que estes homens vivenciam socialmente em virtude de sua vaidade, e acabam internalizando estes comportamentos.

"De certo modo ainda existe sim um preconceito da sociedade. 0 pessoal olha diferente para estas pessoas que compram" (Entrevista 11).

As características do consumidor masculino eram evidenciadas, demonstrando que o homem é objetivo e sai para comprar aquilo que demanda no momento. Para a pergunta "Quando um homem sai para comprar cosméticos, ele..." as respostas mais comuns foram "compra", evidenciando a objetividade do homem em comprar efetivamente o que se propôs inicialmente. As respostas podem evidenciar constatações sobre o consumo simbólico, uma vez que "a visão dos consumidores como seres estritamente racionais e motivados pela busca de utilidade é substituída por seu entendimento como alguém que age conforme suas próprias significações, que se permite sonhar" (De Andrade et. al, 2017).

As respostas para a pergunta "Com relação ao uso de produtos cosméticos um homem nunca compra...", as respostas também foram objetivas demonstrando que um homem não compra aquilo ao qual não se dispõe, demonstrando que as compras por impulso são menos observadas nestes casos. As respostas projetavam o cotidiano destes entrevistados em respostas como eu nunca compro..., ou produtos que eles não costumam usar, ou até mesmo produtos que não conhecem. Evidencia-se, portanto, um aspecto do envolvimento do consumidor masculino com produtos cosméticos, já que ele compra o que será efetivamente consumido, ao contrário das mulheres que muitas vezes compram produtos desnecessários as suas reais necessidades. As respostas dos homens para esta questão também demonstra que há evidencias quanto ao consumo destes produtos, já que eles prontamente completavam a frase, salientando o quão acostumados estão com este tipo de compra, do contrário, teriam dificuldades na resposta.

Esses homens, mesmo quando se definem como vaidosos, demonstram uma preocupação de não ultrapassar o limite da vaidade equilibrada para a vaidade excessiva. É como se a vaidade exagerada fosse vergonhosa para os homens que ainda estão envoltos por questões preconceituosas a respeito da vaidade do homem, entendendo que devem estabelecer posturas socialmente aceitáveis e esperadas no convívio em sociedade, e ser muito vaidoso estaria fora destes padrões do gênero masculino. A esse respeito Fontes, Borelli e Casotti (2010) defendem que enquanto o homem consumir menos produtos e serviços de beleza que a mulher, se mantendo dentro dos limites do aceitável, a diferenciação entre os sexos estará garantida. 
"Eu verifico que os homens que frequentam e fazem tratamento de estética que para eles está ótimo, mas é uma situação meio pelo lado feminino" (Entrevista 01).

No entanto, alguns desses entrevistados, apesar de reprovarem o comportamento exagerado relacionado a vaidade, e dizer que a sua vaidade é normal e não exagerada, parecem ser contraditórios, já que a respeito dos cuidados pessoais, são minuciosos, ao ponto de escolher cremes hidratantes para cada parte do corpo. Comportamento que talvez possa ser caracterizado como uma vaidade exacerbada, do ponto de vista masculino, no qual o homem tenta se aproximar dos padrões femininos de cuidados pessoais.

"Eu utilizo produto cosmético, perfume, desodorante, creme corporal, gel pós barba, hidrante para o rosto, protetor solar, todos estes eu utilizo constantemente. Eu faço as unhas, faço as mãos e os pés toda semana também. Eu me depilo. Eu tenho um creme que é para as mãos, um creme corporal, e outro para os pés. Eu utilizo todos os dias" (Entrevista 01).

"Eu acho normal. Você parar e comprar um produto pra depilar, ou produto para limpeza de pele ou para arrumar o cabelo, é (pausa) como para qualquer outra coisa" (Entrevista 09).

Muitas vezes esses homens relatavam o preconceito sofrido por eles somente pelo fato de usarem o produto e por serem vaidosos, imperando ainda a visão machista da sociedade, no qual o homem deve manter certos padrões de comportamento.

"Preconceito vai ter sim, porque tem gente que tem a mente fraca, vai levar para o outro lado, entendeu? Mas eu acho que tem preconceito sim, mas eu acho que isso também não vai fazer com que a pessoa deixe de ter vaidade" (Entrevista 05).

"Eu acho uma grande bobagem, porque o cara, na minha opinião, vamos dizer entre aspas, é homem, ele não tem que ficar comprovando. Vamos dar um exemplo: eu sou homem. Eu gosto de me cuidar. Eu tenho que ficar provando para os outros que eu sou aquilo. Então eu uso as coisas que me agrada. Os produtos de beleza que me agrada. E não é por causa de algumas pessoas falando, outras, que eu vou mudar o jeito não. Continuo da mesma forma. Cuidando da beleza, do cabelo, da pele e do corpo, neh?!" (Entrevista 10).

Essa questão do preconceito vai ao encontro da teoria de Bourdieu (2012), que evidencia que há na sociedade definições do que é ser verdadeiramente homem, como um senso de honra, virilidade, e é como se essa visão distorcida do metrossexual evidenciasse as questões de identidade de gênero. Contudo, Oliveira (2008) considera que o metrossexual fomenta uma nova construção de identidade de gênero, no qual as identidades não são mais engessadas como antigamente (Louro, 1999).

"Acaba que tem uma crítica muito grande porque o homem não aceita ser considerado metrossexual, ele gosta de ser reconhecido como homem vaidoso, responsável, e homem que faz tudo que qualquer outra pessoa poderia fazer. Ah, ele é um metrossexual, ah ele é um gay, e usam piadas críticas que acabam que a pessoa fica um pouco constrangido em relação a isso" (Entrevista 01).

"Quando você pensa metrossexual, você associa com homossexual porque as pessoas não sabem o significado e talvez eu também não saiba. Do jeito que eu vejo o metrossexual, nada mais é que um homem que cuida muito da aparência, então não há uma relação entre o metrossexual e o homossexual, embora tenha algumas coisas que o homossexual faz que o metrossexual também faz. Mas tem muitas coisas que o homem faz que o metrossexual também faz. Não quer 
dizer que o cara é metrossexual que ele é homossexual. São coisas diferentes" (Entrevista 02).

"Com certeza tem (preconceito) porque as pessoas ligam o metrossexual com o homossexualismo que não tem nada a ver gente. Nada a ver, nada a ver" (Entrevista 04).

"Geralmente quando um homem é muito vaidoso ele é relacionado ao metrossexual. Então acaba que, como homossexual cuida muito de si, acaba gerando um encontro com o metrossexual e om homossexual porque os dois acabam fazendo o mesmo tipo de coisa, então gera esse preconceito" (Entrevista 09).

Os homens acham que ainda existe uma visão distorcida da sociedade em pensar que o metrossexual é homossexual, mas para alguns deles não existe essa ligação, relatando inclusive que o homem vaidoso pode ser homossexual ou não, mas que ser metrossexual é uma maneira de vivenciar as suas experiências de vaidade e cuidado com a aparência.

Também ao serem estimulados a falar do metrossexual, impera a conotação negativa, que compreendem como um homem extremamente vaidoso, passando dos limites do senso comum que para esses entrevistados é normal da vaidade masculina.

"O metrossexual? Bom, é o que eu já ouvi falar. 0 metrossexual é aquele que é no excesso, vaidoso ao excesso. Ao extremo" (Entrevista 04).

"Ah vaidosa ao extremo, creio. Eu acho que deve ser uma pessoa bem detalhista" (Entrevista 11).

Ademais, ao ouvirem falar sobre o conceito do metrossexual, alguns reconheceram ser o homem descrito um metrossexual e ao dizer como seria este homem, definiram como um homem vaidoso, que cuida criteriosamente da imagem, por meio de cuidados estéticos e produtos cosméticos. 0 interessante nesse ponto é poder fazer conexões entre o que disseram anteriormente os entrevistados. Antes de falar em metrossexual e vaidade exagerada, é unanime a importância dada por todos sobre a necessidade de cuidar da imagem e dizer que um homem que se cuida, seja qual for os seus critérios, está de acordo com os parâmetros de beleza atuais. Entretanto, como reprovam a vaidade exagerada e atribuem ao metrossexual uma personificação do homem feminino e exagerado nos cuidados com a vaidade, naturalmente esses homens não se reconhecem nesse perfil, mesmo que a descrição do metrossexual feita por estes homens demonstram características claras de cuidados idênticas as que estes homens têm no dia a dia. Para Oliveira (2008), isso tem a ver com a subjetividade desse homem na tentativa de transferir o preconceito para outro homem.

Foi apresentado aos entrevistados o conceito do metrossexual de Oliveira Junior (2012). Questionou-se: Como você nomearia o homem preocupado com a aparência, vaidoso, que gosta de usar produtos de grife, passa creme no corpo, vai à manicure e pedicure, gosta de frequentar shoppings, que sabe sobre moda, gastronomia, vinhos...? Houveram respostas diversas, mas que trazem uma conotação positiva ao metrossexual.

"Um cara que está dentro do contexto que nós estamos vivendo hoje. Acima destas questões de marca a pessoa tem que se preocupar com ela, com a saúde dela, com a higiene dela, ao buscar esse tipo de produto, além de trazer esse tipo de benefício, deixa a pessoa satisfeita, normal que faça o que tem que ser feito" (Entrevista 12)

"Ah homem do Séc. 21, homem moderno, homem de hoje. 0 homem é assim hoje" (Entrevista 08).

Essas percepções positivas acerca do conceito demonstram que esses homens estão abertos a esse perfil de consumidor. Contudo, apesar de dizer que esse é o padrão de beleza do homem, demonstrarem admiração e que se sentem confortáveis com as características desse consumidor. Ao 
serem questionados se são metrossexuais a resposta foi negativa para nove dos entrevistados. Talvez seja porque o comportamento de consumo, conforme citado no conceito, já esteja tão internalizado na vida destes homens que faz com que eles achem esse comportamento normal e admirável, mas não ao ponto de se definirem metrossexuais.

Os entrevistados reconheceram que os homens estão consumindo e gastando cada vez mais, e ampliando dia após dia o horizonte de cuidados.

"Olha, isto é uma situação muito pessoal. Porque tem homens que gastam dinheiro com eles mesmos, por beleza, tratamento de estética, e tem outros que não, gastam porque precisam, shampoo, condicionador, creme para o corpo, o básico. Agora tem pessoas que tem uma cisma com eles mesmos e gastam um dinheiro maior em questão de estética se preocupando, então vai muito do perfil de cada um" (Entrevista 01).

"Eu acho que esse número tem aumentado. Ultimamente a gente vê notícias de pessoas preocupadas inclusive com depilação, que era uma coisa muito feminina, hoje em dia o homem gasta mais com isso, muitas coisas que eram muito femininas e hoje o homem está gastando, mas eu não sei se chega a ser tanto quanto as mulheres" (Entrevista 02).

"Os homens tem gastado cada vez mais" (Entrevista 06).

Os homens desse grupo declararam que não se envergonham por consumir produtos cosméticos, e complementam gostar desse consumo, além de acreditar que assim como vem aumentando gradativamente o cuidado masculino com relação a beleza, inversamente reduzirá o preconceito das pessoas com relação ao uso destes produtos por homens. Para eles o metrossexual investe massivamente também em produtos cosméticos.

"Roupas estilosas, produtos de limpeza para pele, para o corpo. 0 que é bom para os pés, para as mãos, para o cabelo, coisas para passar até no rosto. Um amigo passava pó de arroz. Talvez acessórios, para a orelha para o braço. Cores do momento" (Entrevista 02).

"Tem que estar sempre bem vestido, qualquer ocasião. (...) Se olha muito no espelho, se olha muito no espelho e gasta um dinheiro até considerável com ele, tanto de cosmético, salão, academia, suplemento. É rede social também, o cara posta muita foto dele" (Entrevista 08).

Nesse exercício de caracterizar o metrossexual, os homens acabavam se enxergando como metrossexuais, pois entendiam que muitas das rotinas eram similares àquelas que eles próprios tinham no dia a dia. Esses relatos eram por vezes confessados após o término das entrevistas, e eram destacadas, principalmente, as questões sobre o preconceito que estão enraizados ao se falar de metrossexual.

"Provavelmente talvez pelo fato de eu saber tudo isso também talvez eu seja um metrossexual (risos)" (Entrevista 06).

É possível dizer que todos os homens entrevistados são vaidosos, claro que uns mais que outros. Contudo, a vaidade exagerada, que na visão deles não é bem-vinda, seria um comportamento associado ao metrossexual, e por isso, na visão deles, não seria adequado dizer que eles são metrossexuais, apesar de se encaixarem no conceito apresentado por Oliveira Junior (2012).

\section{CONSIDERAÇÕES FINAIS}

Nos discursos e a partir da análise de conteúdo proposta, tornou-se possível inferir que existe um movimento migratório do consumo de produtos de beleza, antes dominado pelo público feminino, 
mas que vem aumentando e contribuído para uma mudança no perfil de consumo dos homens. Apesar de ainda ser um comportamento de compra que enfrenta preconceitos, o homem hodierno está em busca de uma ruptura dessa visão ultrapassada e que tem sido uma barreira para esse sujeito expressar a sua vaidade com total tranquilidade sem ser sub significado pela sociedade. Entretanto, há, também, por parte desses homens, um julgamento sobre a sua própria vaidade e a vaidade do outro, em que por vergonha de ser reconhecido como metrossexual, conceito envolto por preconceitos e erros na conotação inadequada de gênero, se conceitua como vaidoso equilibrado antes mesmo de refletir sobre o seu próprio consumo.

De fato, para a literatura, o homem metrossexual é entendido como um homem muito vaidoso, e que usa produtos de beleza para melhorar a sua aparência, sendo este um dos fatores que caracteriza a sua vaidade. Portanto, analisando somente pela esfera do consumo, não se encontrou nessa pesquisa diferenças significativas entre os homens pesquisados e o conceito do metrossexual, uma vez que eles demonstraram hábitos de consumo de produtos cosméticos com grau de prazer hedônico e de envolvimento com tais produtos. Nesse aspecto, a técnica projetiva demonstrou uma relevância significante para tal conclusão.

Percebendo os resultados e dados analisados, e em busca de minimizar o preconceito sobre o metrossexual, propõe-se como contribuição acadêmica a atualização do conceito, uma vez que o metrossexual seria um homem que vislumbra uma aparência jovem e que busca inovar sempre o seu visual, utilizando da moda, produtos de beleza e estar sempre antenado às novas tendências de comportamento de consumo. Atualizar o conceito não foi um objetivo incorporado a essa pesquisa, mas demonstrou ser oportuno diante da evolução da discussão sobre o assunto da vaidade masculina.

Essa pesquisa buscou compreender como os homens percebem os reflexos desse consumo na sociedade atual e, a partir dos resultados, conclui-se que eles por estarem mais vaidosos, estão cada vez mais seguros desse comportamento, apesar de perceberem o excesso de estereótipos envolvidos nesse consumo, uma vez que uma parcela da sociedade ainda enxerga essas mudanças no comportamento do homem como algo estritamente do consumo cotidiano feminino. Por isso, nos momentos em que o assunto preconceito foi abordado ou naturalmente colocado pelos entrevistados, eles buscavam expressar ou efetivamente declarar a sua masculinidade ou do homem vaidoso, negando a ligação direta e incorreta entre esse tipo de consumo e a identidade de gênero homossexual. Era como se eles quisessem dizer: "Eu sou vaidoso, mas sou homem com H". Também foi possível entender que na visão deles a vaidade é cuidar da saúde, e uma aparência adequada é importante para os relacionamentos em sociedade, sendo esses os relacionamentos amorosos, familiares e entre amigos, além do mercado de trabalho. É importante para eles se mostrar bonito em sociedade para ser bem aceito nas relações.

A literatura escassa sobre o tema vaidade masculina na perspectiva do consumo, a seleção dos entrevistados e o processo de realização das entrevistas mostraram-se como limitações desse estudo. No processo de realização das entrevistas, o fator limitante mais latente foi investigar homens vaidosos. Muitos homens se sentiam acanhados em falar sobre sua vaidade, porém, ao explicitar o teor acadêmico do estudo, apesar do desconforto de alguns, esses homens aceitavam contribuir com a pesquisa. Contudo, o homem é ansioso e algumas vezes demonstra-se muito objetivo nas respostas, aumentando o tempo de realização da entrevista em vários casos, para que fosse possível absorver um pouco mais do universo de consumo desse homem.

Esse estudo contribui ainda para uma reflexão sobre o consumo simbólico do consumidor masculino e que poderá ser analisado por outras vertentes de pesquisa por demonstrar ser um tema rico, e que possibilitará desencadear analises sob as várias temáticas de estudo do comportamento do consumidor.

\section{Referências}

Aaker, D. A., Kumar, V., \& Day, G. S. (2001). Pesquisa de marketing. São Paulo: Atlas. Aaker, D. A., Kumar, V., \& Day, G. S. (2004). Pesquisa de marketing (2ª ed.). São Paulo: Atlas. 
Abdala, P. R. Z. (2008). Vaidade e consumo: Como a vaidade física influencia o comportamento do consumidor (Dissertação de Mestrado).Universidade Federal do Rio Grande do Sul, Porto Alegre, RG, Brasil.

ABIHPEC. (2016). Panoroma do Setor de HPPC. Recuperado de https://abihpec.org.br/publicacao/panorama-do-setor-2016-2/.

Bardin, L. (2004). Análise de conteúdo. Lisboa: Edições 70.

Bastos, R. E. (2005). A influencia feminina no consumo masculino de cosméticos. Faculdade Ibmec, Rio de Janeiro, RJ, Brasil.

Bauer, M. W., \& Aarts, B. (2002). A construção do corpus: um princípio para a coleta de dados qualitativos. In: Bauer, M., \& Gaskell, George. Pesquisa qualitativa com texto, imagem e som. Petrópolis: Vozes.

Baudrillard, J. (2003). A Sociedade de Consumo. Lisboa: Edições.

Belk, R. W. (1988). Possessions and the Extended Self. Journal of Consumer Research, 15(2), 139-168.

Bodart, C. N. (out-dez de 2014). Vaidade masculina na modernidade. Revista Posição, 1(3), 24-27.

Bond, D., \& Ramsey, E. (2010). The role of information and communication technologies in using projective techniques as survey tools to meet the challenges of bounded rationality. Qualitative Market Research: An, 13(4), 430-440.

Bourdieu, P. (2012). A Dominação Masculina.Rio de Janeiro: Bertrand Brasil.

Butler, J. (2003). Problemas de genero: feminismo e subversão da identidade (R. Aguiar,Trad.). Rio de Janeiro: Civilização Brasileira. (Obra original publicada em 1990).

Campbell, C (2001). A ética romântica e o espírito do capitalismo moderno. Rio de Janeiro: Rocco.

Campbell, C. (2006). Eu compro, logo sei que existo: as bases metafisicas do consumo moderno. In: (Barbosa, L. \& Campbell, C.) Cultura, consumo e identidade: Rio de Janeiro: Editora FGV.

Carvalho, J. D. R. (2010). Vaidade masculina: um estudo exploratório sobre a mudança de hábitos do homem contemporâneo (Monografia). Centro Universitário de Brasilia, UNICEUB. Brasilia, DF, Brasil.

Castro, F. N. C. (2011). A aparencia como arma social: Um estudo exploratório sobre o comportamento de consumo masculino de produtos de cuidados pessoais (Dissertação de Mestrado). Pontifícia Universidade Católica, Rio de Janeiro, RJ, Brasil.

Ceotto, E. C. (2013). De John Wayne a David Beckham - ressignificações das masculinidades: um estudo em representações sociais (Tese de Doutorado). Universidade Federal do Espirito Santo, Vitória, ES, Brasil.

Cheng, F. S., Ooi, C. S., \& Ting, D. H. (2010, february). Factors affecting consumption behavior of metrosexual: Toward Male Grooming Products. International Review of Business Research Papers, 6, 574-590.

Comassetto, B. H., Solalindez, G. P., Souza, J. V. R, Trevisan, M., Abdala, P. R. Z., \& Rossi, C. A. V. (2012). Nostalgia, anticonsumo simbólico e bem-estar: a agricultura urbana. RAE - Revista de Administração de Empresas, 364.

Connell, R. W., \& Messerschimidt, J. W. (2005). Hegemonic Masculinity: Rethinking the Concept. Gender Society, p. 19.

Connell, R. (2012). Masculinity research and global change. MSC - Masculinities and Social Change,1 (1).

Creswell, J. W. (2003). Research design: qualitative, quantitative and mixed method approaches. Thousand Oaks, Califórnia: Sage.

Davidovitsch, L. (2007). Antecedentes e consequencias dos niveis de envolvimento masculino com vestuário: Uma pesquisa empírica com homens do Rio de Janeiro (Dissertação de Mestrado). Pontifícia Universidade Católica, Rio de Janeiro, RJ, Brasil.

De Andrade, M. L. Pinto, M. R. Leite, R. S. Batinga, G. L., \& Joaquim, A. M. (2017). 0 consumo simbólico e o espírito hedônico do consumidor moderno de iogurtes. Revista Pensamento e Realidade, 32(3).

Dion, K., Berscheid, E., \& Walster, E. (1972). What is beautiful is good. Journal of Personality and Social Psychology, 24(3), 285-290.

Easterby-smith, M., Thorpe, R., \& Lowe, A. (1999). Pesquisa gerencial em administração. São Paulo: Pioneira. 
Fontes, A. F., Borelli, F. C., \& Casotti, L. M. (2010). Como ser homem e ser belo? Um estudo exploratório sobre práticas masculinas de consumo de beleza. In: XXXIV Encontro da ANPAD. Rio de Janeiro.

Freitas, L. K. M. R. (2011, março). Novos modos de (a)enunciar o masculino na mídia: o discurso da publicidade sobre o metrossexual, Revista Litteris, 7.

Fritz, M., \& Gomes de Souza, C. (2006, setembro). Inovação na indústria de cosméticos: Casos de empresas no setor. Anais do XXXIV Congresso Brasileiro de Ensino de Engenharia, Passo Fundo, RJ, Brasil.

Gama, M. G., Silva, C. L., \& Vasconcelos, R. M. (2011, abril). Homens: Os novos consumidores de moda. Anais do World Congress on Communication and Arts, São Paulo, SP, Brasil.

Garboggini, F. B. (1999). O homem no espelho da publicidade. Reflexão e refração da imagem masculina na publicidade televisiva brasileira nos anos 90 (Tese doutorado), ECA-USP, 1999.

Garboggini, F. B. (2008). In: Maria Ines Ghilardi-Lucena e Francisco de Oliveira. (Org.). Representações

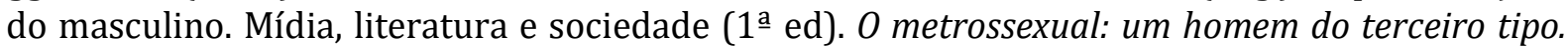
Campinas: Alinea, 1, 77-92.

Garcia, W. (2004). O Corpo contemporâneo: A Imagem do metrossexual no Brasil. MEMME, Revista de Humanidades, 5(11).

Garcia, W. (2011). O metrossexual no Brasil: Estudos contemporaneos. São Paulo: Factash.

Gaskell, G. (2002). Entrevistas individuais e grupais. In: Bauer, M. W., \& Gaskell G. Pesquisa qualitativa com texto, imagem e som: um manual prático. Petrópolis: Vozes.

Gikovate, F. (1987). Vício dos vícios: um estudo sobre a vaidade humana. São Paulo: MG Editores Associados.

Gikovate, F. (1989). Homem: o sexo frágil? São Paulo: MG Editores Associados.

Goldenberg, M. (2000). In: __ (org). Os novos desejos: das academias de musculação às agências de encontros. $O$ Macho em Crise: Um Tema de debate dentro e fora da academia.Rio de Janeiro: Record.

Gouveia, T. M. (2006). Os homens e seus carrinhos... de compras: um estudo sobre o comportamento do consumidor masculino no supermercado (Dissertação de Mestrado). Faculdade Ibmec, Rio de Janeiro, RJ, Brasil.

Haire, M. (1950, Apr.). Projective techniques in marketing research.Journal of Marketing, Chicago, $14(5)$.

Infante, V. H. P., Calixto, L. S., \& Campos, P. M. B. G. M. (2016). Comportamento de homens e mulheres quanto ao consumo de cosméticos e a importância na indicação de produtos e adesão ao tratamento. Surgical \& Cosmetic Dermatology, 8(2), 134-141.

Kacen, J. J. (2000). Girrrl power and boyyy nature: the past, present, and paradisal future of consumer gender identity. Marketing Intelligence e Planning, 18(6), 345-355.

Kim, J., Han, W., Kim, D. T., \& Paramita, W. (2013). Is beauty in the eye of the beholder? Gender and beauty in the cosmetics sector: A comparative study of Indonesia and Korea. Marketing Intelligence and Planning, 31(2), 127-140.

Kyung, S. B. (2012). The impact of consumer innovativeness, attitude, and subjective norm on cosmetic buying behavior: evidence from APU female students (Master's Thesis). Ritsumeikan Asia Pacific University, Beppu, Oita, Japan.

Levy, S. J. (1959). Symbols for Sale. Harvard Business Review, 37, 117-124.

Lipovetsky, G. (1944). A felicidade paradoxal: ensaio sobre a sociedade de hiperconsumo. São Paulo: Companhia das Letras.

Loizos, P. (2002). Vídeo, filme e fotografias como documentos de pesquisa. In: Bauer, M. W.; Gaskell, G. (Eds.) Pesquisa qualitativa com texto, imagem e som: um manual prático. Petrópolis: Ed. Vozes.

Louro, G. L. (1999). Pedagogias da Sexualidade. In: Louro, G. L. (Org.) . O Corpo educado: pedagodias da sexualidade. Belo Horizonte: Autêntica.

Louro, G. L. (1999). Pedagogias da Sexualidade. In: Louro, G. L. (Org.) . O Corpo educado: pedagodias da sexualidade. Belo Horizonte: Autêntica.

Lubeck, R. M. Hopner, A. Schröeder, C. D. Wittmann, M. L., \& Nogueira Luiz, L. (2018). Consumo simbólico: análise de um grupo de consumidores de baixa renda em Porto Alegre. Organizações em contexto, 14(28), 145-175. 
Lucerna, M. (2006). Relações de gênero: A dominação masculina. São Paulo.

Malhotra, N. (2001). Pesquisa de marketing: uma orientação aplicada. Porto Alegre: Bookman.

Malhotra, N. (2011). Pesquisa de Marketing: foco na decisão.São Paulo: Pearson Education,3 ed.

Marre, J. (1991). História de vida e método biográfico. Cadernos de Sociologia, 3(3), 55-88.

Maximo, A. R. (2015). Estudo do comportamento do consumidor metrossexual com relação ao consumo de produtos cosméticos (Dissertação de Mestrado). Pontifícia Universidade Católica, Belo Horizonte, MG, Brasil.

Maximo, A. R., \& Leite, R. S. (2017). Novas concepções de gênero: 0 homem vaidoso e os tipos de consumidores metrossexuais. Consumer Behavior Review, 1(Special Edition), 62-79.

Maximo, A. R., \& Leite, R. S. (2019). A identidade metrossexual de homens consumidores de produtos de beleza. Comunicação \& Mercado - Revista Internacional de Ciências Sociais Aplicadas da UNIGRAN, v. 6, p. 1-100.

Michael Weber, J., \& Villebonne, J. C. (2002). Canadian and French men's consumption of cosmetics: a comparison of their attitudes and motivations. Journal of Fashion Marketing, 6(4), 396-407.

Neri, R. F., \& Tarquini, J. R. (2011, julho). Todos Querem Ser David Beckham - O “Novo Homem” É Fruto Da Mídia Ou Da Sociedade?. Anais do Intercom - XXII Prêmio Expocom 2015, Rio de Janeiro, RJ, Brasil.

Nobusada, D., Vieira, E., Silva Leite, J., Xavier, M. C., Rafare, M. R., \& Carneiro, M. M. (2011, julho). 0 homem metrossexual e o seu comportamento de compra de cosméticos. Anais do ENFAGEN, Uberlandia, MG, Brasil.

Nossiter, V., \& Biberman, G. (1990) Projective drawings and metaphor: analysis of organizational culture. Journal of Management Psychology, London, MCB University Press, 5(3), 13-16.

Oliveira, M. A. (2008). O homem no espelho: Uma busca de comprrensão da identidade metrossexual (Dissertação de Mestrado). Faculdade Boa Viagem, Recife, PE, Brasil.

Oliveira, M. A., \& Leão, A. L. (2011). O papel da subjetividade na construção da identidade metrossexual. Revista de Negócios, 10(1), 177-202.

Oliveira, M. A., \& Leão, A. L. (2012). Sendo aos olhos do outro: o papel da alteridade na construção da identidade metrossessual. Revista de Administração 4(2), 264-274.

Oliveira Junior, E. B. (2012). Masculinidades em cena: O mode de ser e de pensar o metrossexual a partir das telenovelas (Dissertação de Mestrado).Universidade Federal do Pará, Belém, PA, Brasil.

Papalia, D. E., Olds, S. W., Feldman, \& R. D. (2006). Desenvolvimento Humano. Porto Alegre: Artmed.

Penn, M. (2008). Microtendências. Rio de Janeiro: BestSeller.

Pinho, 0. (2004). Qual é a identidade do homem negro? In: Democracia Viva, p. 22.

Piacentini, M., \& Mailer, G. (2004). Symbolic consumption ethnocentrism when foreign products are better. Journal of Consumer Behavior, 3(3), 251-162.

Popcorn, F., \& Marigold, L. (1997). Click: 16 tendências que irão transformar sua vida, seu trabalho e seus negócios futuros. Rio de Janeiro: Campus.

Resende, S. P., Pinto, M. R., Maximo, A. R., \& Leite, R. S. (2014, setembro). "Eu vou, eu vou... Pro Shopping agora eu vou": Os significados dos Shopping Centers para os consumidores da nova classe média. Anais VII ENEC, Rio de Janeiro, RJ, Brasil.

Sant'anna, P. (2005). Revistas de moda masculinidade e a ambigüidade nos anos noventa. In: WAJNMAN S e ALMEIDA A J de (Orgs.) Moda, Comunicação e Cultura (2ª ed.). São Paulo: Arte e Ciência.

Sayon, M. (2017). Consumo de cosméticos masculinos: Uma questão de vaidade e masculinidade? (Dissertação de Mestrado). Escola Superior de Propaganda e Marketing, São Paulo, SP, Brasil.

Seltiz, C., Wrightsman, L., \& Cook, S. (1976). Research methods in social relations (3 ed.). Holt: Rinehart e Winston Inc.

Slater, D. (2002). Cultura do consumo e modernidade. São Paulo: Nobel.

Souiden, N., \& Diagne, N. (2009). Canadian and French men's consumption of cosmetics. Journal of Consumer Marketing, 26 (2), 97-109.

Vergara, S. C. (2008). Métodos de pesquisa em administração. São Paulo: Atlas.

Vieira, V. A., \& Tibola, F. (2005, Abr/Jun). Pesquisa qualitativa em marketing e suas variações: trilhas para pesquisas futuras. Revista de Administração Contemporânea, Curitiba, 9(2), 9-33. 
Vieira-Senna, T. (2011). A Construção da identidade masculina contemporânea por meio da roupa intima (Dissertação de Mestrado). Universidade Anhembi Morumbi, São Paulo, SP, Brasil.

Villaça, N. (2011). In: (Garcia W.) O metrossexual no Brasil: Estudos Contemporâneos.São Paulo: Factash. Woodward, K. (2000). Identidade e diferença: Uma introdução teórica e conceitual. In: Silva, T. T. (org). Identidade e diferença: A perspectiva dos estudos culturais. 